Produto \& Produção, vol. 5, n. 3, p. 17-32, out. 2001

\title{
Problemas de scaling up no desenvolvimento de produtos farmacêu- ticos em empresas brasileiras
}

\author{
Istefani Carísio de Paula, M.Sc. \\ Doutoranda do Programa de Pós-Graduação em Engenharia de Produção-UFRGS \\ e-mail: istefani@ppgep.ufrgs.br
}

José Luis Duarte Ribeiro, Dr. Eng.

Programa de Pós-Graduação em Engenharia de Produção-UFRGS

e-mail: ribeiro@ufrgs.br

\begin{abstract}
Este trabalho apresenta uma análise do desenvolvimento de produtos em empresas farmacêuticas e dos principais fatores operacionais que afetam o scale up de produtos líquidos, semi-sólidos e sólidos. Tais problemas são freqüentes e pouco relatados na literatura, por se caracterizarem como conhecimento tácito, adquirido com a experiência prática e transferido de profissional para profissional no ambiente de produção. A importância deste artigo reside na compilação e registro das principais causas e soluções para problemas de scale up encontradas por profissionais, durante a fabricação de formas farmacêuticas, uma vez que tais problemas podem comprometer a fabricação e o efeito farmacológico do medicamento. Além disso, permite fazer um diagnóstico preliminar das condições de funcionamento dos setores de desenvolvimento de produtos em empresas farmacêuticas. Esta análise é realizada a partir das experiências de três farmacêuticos industriais e as informações foram coletadas em entrevistas individuais. Os farmacêuticos foram questionados a respeito dos tipos de produto que fabricam, tipos de equipamentos que empregam nas escalas de bancada, piloto e produção, e alterações de especificação verificadas nas formas farmacêuticas durante a transferência de escala.
\end{abstract}

Palavras- chave: scale up; desenvolvimento de produto; produto farmacêutico; entrevistas qualitativas.

This paper presents an analysis of the procedures used in product development in Brazilian pharmaceutical companies. Its objective is to formalize the tacit knowledge that experts acquire solving dosage form quality problems, which arise throughout the product development and the production scale transferences. These problems are called scale up problems and include dosage form physical properties modification with possible pharmacological effect loss. Qualitative interviews were applied to three pharmacists aiming to identify the operational factors which influence the dosage forms in scaling up procedures. The questions presented to the pharmacists were: type of products under development (solid, semisolid or liquid); equipment available for pilot studies and for large scale production; and most frequent scaling up problems observed in dosage forms during scale transference.

Keywords: scale up; product development, pharmaceutical forms; qualitative interviews.

\section{Introdução}

Scale up pode ser definida como a partida e operação bem sucedidas de uma unidade de produção industrial, cujos procedimentos de operação e desenho estejam, "em parte", baseados em experimentação e demonstrações realizadas em menores escalas (Bisio e Kabel,1985). Tratando-se de processos farmacêuticos, a transferência de uma escala de bancada para escala industrial é quase sempre problemática (Ogawa, et al., 1994), especialmente em formulações sólidas e semi-sólidas.
As formulações sólidas são produzidas a partir de operações como redução de partículas, mistura de pós, compactação e revestimentos, enquanto as semisólidas passam por operações de aquecimento, agitação, resfriamento, envase, etc. Essas operações, apesar de serem usadas em escala de bancada, não necessariamente serão reproduzidas na escala industrial. Muitas vezes, as formulações otimizadas em escala de bancada apresentam alterações de suas propriedades físicas quando produzidas na planta industrial. Isso pode gerar uma série de transtornos, obrigando a equipe a retornar ao desenvolvimento do 
produto e trazendo incertezas a respeito da qualidade do produto final que será obtido.

A literatura científica procura tratar o problema de forma racional. Encontra-se um número razoável de artigos, (Klein, 1999; Bueb, Warnke, Bauer, 1994; Wehrlé, 1993; Von Zimmermann, 1991; Hofen, Körfer, Zetzmann,1990; Nyqvist, 1989; Bisio e Kabel, 1985) nos quais os problemas de scaling up são contornados através de estudos comparativos entre equipamentos usados nas operações de transformação, ou de estudos que reduzem os efeitos indesejados de scaling up, através de alterações nas formulações propriamente ditas. De qualquer forma, as soluções apresentadas ainda são poucas e não possuem suficiente generalidade. Assim, a grande maioria das empresas nacionais resolve tais questões através da tentativa e do erro.

Por um outro lado, a técnica de tentativa e erro gera uma carga de experiência para o pessoal da produção, que não pode ser desprezada. Alguns autores argumentam que quando o pesquisador não "constrói uma ponte" entre o seu conhecimento e a experiência do profissional, é muito comum que experimentos industriais não ocorram exatamente como esperado e que venham inclusive a falhar (Coleman e Montgomery, 1993; Gunter, 1993).

Diante do exposto, julgou-se oportuno e necessário realizar um levantamento junto aos profissionais do desenvolvimento e produção de produtos farmacêuticos, questionando: (i) quais as principais alterações ocorridas em formulações durante o scaling up, e (ii) quais os fatores operacionais responsáveis pelas alterações das características de qualidade das mesmas.

\section{Fases do desenvolvimento de produtos farmacêuticos}

Uma vez que as operações envolvidas na preparação de produtos farmacêuticos sólidos, líquidos e semisólidos têm características peculiares, vinculadas ao produto e ao volume de produção, é conveniente apresentar, de forma sucinta, as operações envolvidas no desenvolvimento e na produção destes.

As fases que compõem o desenvolvimento formal de uma forma farmacêutica são denominadas de:

1. Etapa de pré-formulação (quando se parte de um fármaco ou substância ativa nova);

2. Etapa de formulação (testes de bancada para seleção dos melhores adjuvantes);

\section{Etapa de estabilidade acelerada ou stepping up}

(estabilidade acelerada em bancada e compatibilidade entre substância ativa e adjuvantes)

4. Scaling up (transferência para a escala piloto ou industrial);

5. Controle de processo (fase industrial);

6. Validação do processo (provar que o processo faz aquilo que se espera dele)

7. Estudo de estabilidade em prateleira (degradação do produto antes do seu uso)

\section{Registro do produto e lançamento no merca-} do.

O desenvolvimento da formulação na etapa 2 pressupõe operações físicas destinadas a incorporar a(s) substância(s) farmacologicamente ativa(s) num meio inerte, denominado veículo (líquido); base (semisólido) ou excipiente (sólido), os quais, por sua vez, são constituídos por substâncias inertes denominadas adjuvantes. Considera-se a formulação desenvolvida e otimizada quando se encontra a melhor combinação de adjuvantes para o veículo, para a base ou para os excipientes.

Durante a transferência de escala, na etapa 4, são relatadas queixas dos encarregados de desenvolvimento e produção sobre alterações nas características do produto anteriormente otimizado em escala de bancada. Para facilitar a compreensão destas alterações, serão descritos, de forma esquemática, processos produtivos de formas líquidas, sólidas e semisólidas.

\section{Processos produtivos}

\subsection{Processo produtivo de formas farma- cêuticas líquidas}

A Figura 1 ilustra as operações envolvidas na produção de formas farmacêuticas líquidas. A primeira operação é a pesagem dos insumos ativos e adjuvantes (1); a segunda etapa consiste na transferência dos adjuvantes para tanque de mistura (2); o sistema de aquecimento é opcional dependendo da solubilidade dos adjuvantes presentes no produto (3); a quarta operação acontece no tanque de mistura ao qual se encontra acoplado um sistema de agitação (4); a quinta operação envolve a adição da(s) substância(s) ativa(s); e, por fim, a operação de homogeneização acompanhada ou não de aquecimento (6).

A etapa 2 (Figura 1) é fundamental para determinar o tipo de forma líquida, pois trata-se da preparação do veículo que receberá os componentes ativos. De forma generalizada pode-se dizer que, se os adjuvantes forem açúcares, o produto será um xarope; 


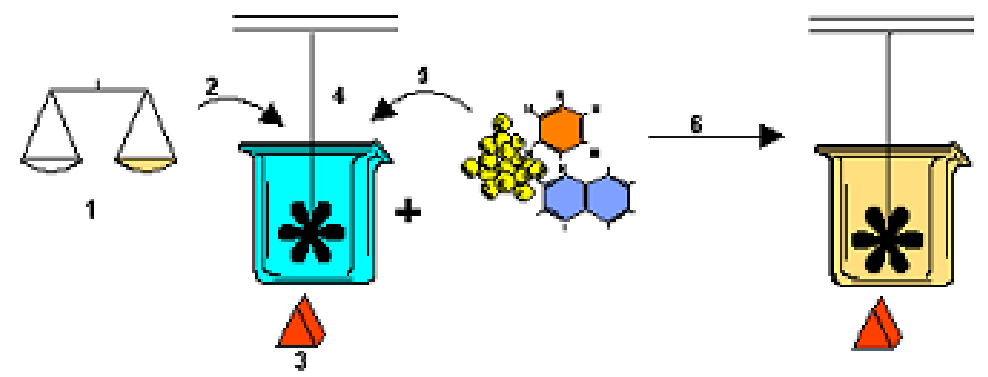

Figura 1 - Processo de produção de formas farmacêuticas líquidas

se os adjuvantes forem agentes de viscosidade, este será um veículo para suspensão (Figura 2B), se forem misturas de açúcares-álcool-agentes de viscosidade, será um elixir, e assim por diante. As soluções são caracterizadas por solubilidade total dos ativos e adjuvantes no veículo (Figura 2A) e as suspensões (Figura 2B) pela insolubilidade do componente ativo no veículo, situação na qual é imprescindível empregar adjuvantes doadores de viscosidade, para reduzir a velocidade de sedimentação, mantendo o componente ativo, tanto quanto possível, homogeneamente disperso no veículo.

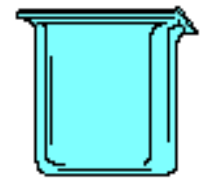

A.

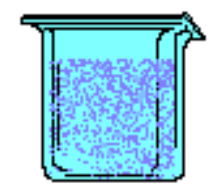

B
Figura 2 - A: representação de solução- componentes ativos e adjuvantes totalmente solúveis no solvente; B: suspensão componente ativo insolúvel e disperso no solvente viscoso

\subsection{Processo produtivo de formas farma- cêuticas semi-sólidas}

Na preparação de formas líquidas, a necessidade ou não de aquecimento é função da menor ou maior solubilidade do componente ativo. Na preparação de semi-sólidos, o aquecimento é fundamental, pois as substâncias lipofílicas empregadas (como ceras e álcoois graxos), precisam ser fundidas e homogeneizadas com água e tensoativos (no caso das emulsões) ou simplesmente fundidas para receber o componente ativo (no caso das pomadas).

A Figura 3 ilustra o processo de preparação de cremes, pastas e pomadas. A primeira operação consiste na pesagem das ceras e adjuvantes (1); em seguida transferência das ceras e adjuvantes para um tanque de mistura provido de sistema de aquecimento (2); na terceira operação ocorre a transferência de água (no caso de emulsões) para o tanque (3); a quarta etapa consiste na operação de mistura (tanque+agitação+aquecimento) (4); na quinta etapa se dá a transferência da (s) substância (s) ativa (s) para o tanque (5); seguida de homogeneização (6); por fim, executa-se uma homogeneização em moinhos (7).

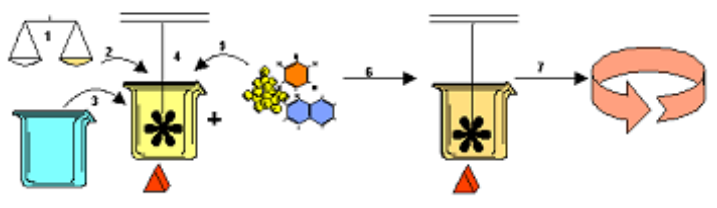

Figura 3 - Processo de preparação de formas farmacêuticas semi-sólidas

A etapa de homogeneização em moinho (7), com o produto ainda quente, é fundamental para criar partículas pequenas das fases aquosa, oleosa e tensoativos, bem como do componente ativo, o que se reflete significativamente sobre a estabilidade da emulsão. Quando esta etapa não é satisfatoriamente cumprida, ocorre "quebra" do sistema, com separação entre as fases aquosa e oleosa (sobrenadante). No caso das pomadas (fase oleosa apenas), o moinho garante a redução das partículas do componente ativo, conferindo um aspecto homogêneo ao produto.

\subsection{Processo produtivo de formas farma- cêuticas sólidas}

O processo de produção de comprimidos pode ser realizado por compressão direta de pós ou pela compressão de grânulos. Alguns tipos de pós apresentam características elásticas, não permanecendo compactados após a compressão. Estes tipos de pós devem ser granulados, ou seja, aglutinados com o emprego de líquidos (granulação via úmida) ou simplesmente por compactação (granulação via seca). O grânulo obtido é, então, transformado em comprimido. A Figura 4 ilustra a granulação via úmida, já que esta é mais freqüente nas empresas brasileiras. 


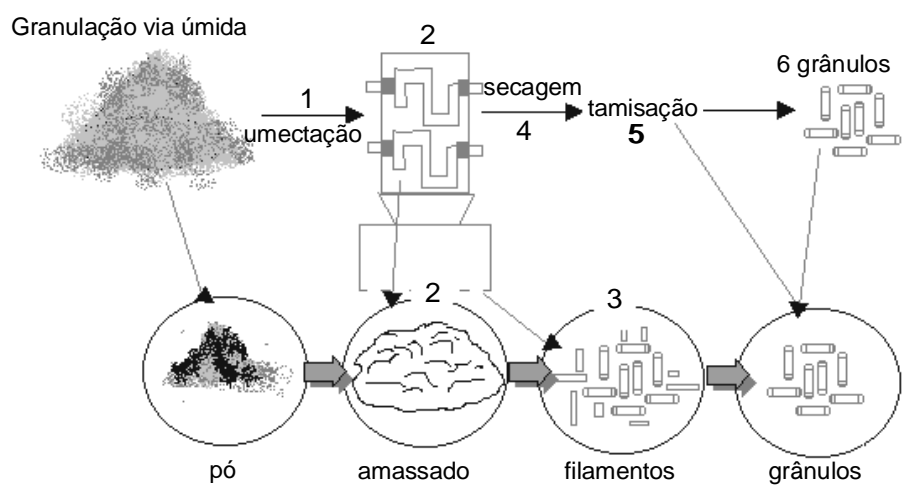

Figura 4 - Granulação via úmida (Villa Jato, 1997)

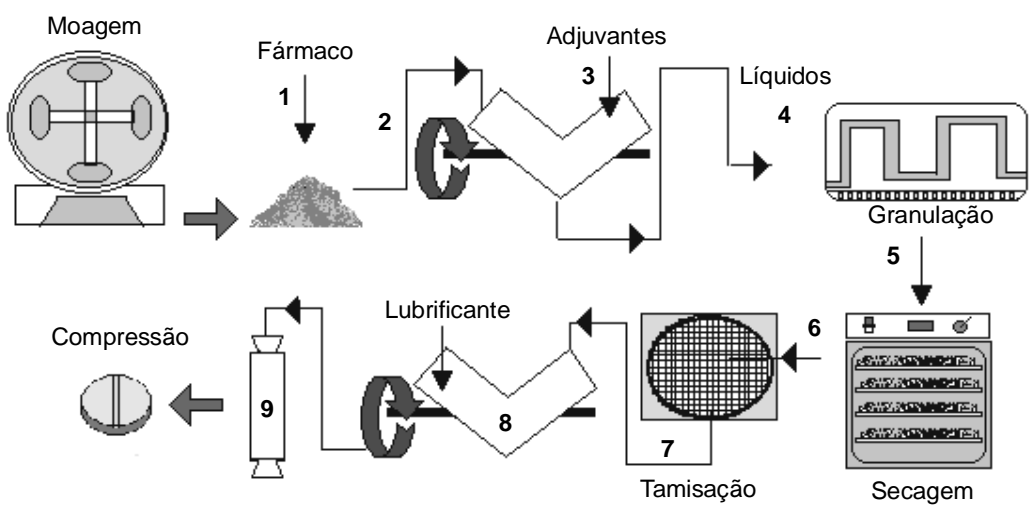

Figura 5 - Preparação de comprimidos por via úmida (Villa Jato, 1997)

A primeira etapa do processo de granulação envolve o umedecimento do pó e mistura em malaxador (produção de uma massa) (1 e 2), seguida de extrusão através de placa perfurada ou tamis para fabricação de filamentos (3); posteriormente, realizase a secagem dos filamentos em estufa (4) e a calibração do grânulo por tamisação (5) (homogeneização do tamanho do grânulo em peneiras) (6) (grânulo acabado).

O esquema da Figura 5 ilustra o processo de compressão quando se faz uma granulação via úmida (etapas de 1 a 7), sendo que na etapa 8 são misturados alguns adjuvantes juntamente com o grânulo para posterior compressão na etapa 9 . Torna-se importante citar os adjuvantes adicionados nas etapas 3 e 8 , já que estes últimos colaboram com a dureza e friabilidade do comprimido. As etapas 1 a 7 correspondem à granulação via úmida citada anteriormente; a etapa 8 consiste na mistura do grânulo com adjuvantes e a etapa 9 corresponde à compressão.

Na etapa 3 adiciona-se um líquido (água com aglutinante; álcool com aglutinante; solução de sacarose) para molhar a substância ativa e o diluente ou material de carga (pó inerte que dá volume ao comprimido). Estas soluções contêm aglutinantes que promovem a aglomeração das partículas dos pós.
As palavras em negrito representam os adjuvantes, presentes nesta fase, que contribuem para a formação de grânulos mais resistentes ou menos resistentes, dependendo do tipo de adjuvante empregado.

Na etapa 8 adicionam-se aos grânulos, num misturador em formato $\mathrm{V}$ ou em forma de $\mathrm{Y}$, lubrificantes e aglutinantes. Os primeiros são adjuvantes que impedem a aderência de pós nos punções da compressora, enquanto que os segundos auxiliam a aglutinar os grânulos para a formação do comprimido.

Conforme se observa, a Figura 6 apresenta a seqüência de produção de comprimidos em compressoras. Primeiramente, o punção superior desce comprimindo pós ou grânulos acondicionados na matriz ou câmara de compressão (A); em seguida mostra-se o punção inferior, que corresponde ao fundo da matriz, (B) e é o responsável pela ejeção do comprimido desta (C). Por fim, ilustra-se o reinicio da alimentação da matriz com nova carga de pós ou grânulos (A).

A dureza e friabilidade são duas características físicas dos comprimidos, determinadas pela influência dos seguintes fatores: força de compressão, tipos de adjuvantes empregados e pela quantidade empregada destes, umidade residual das partículas do grânulo e 


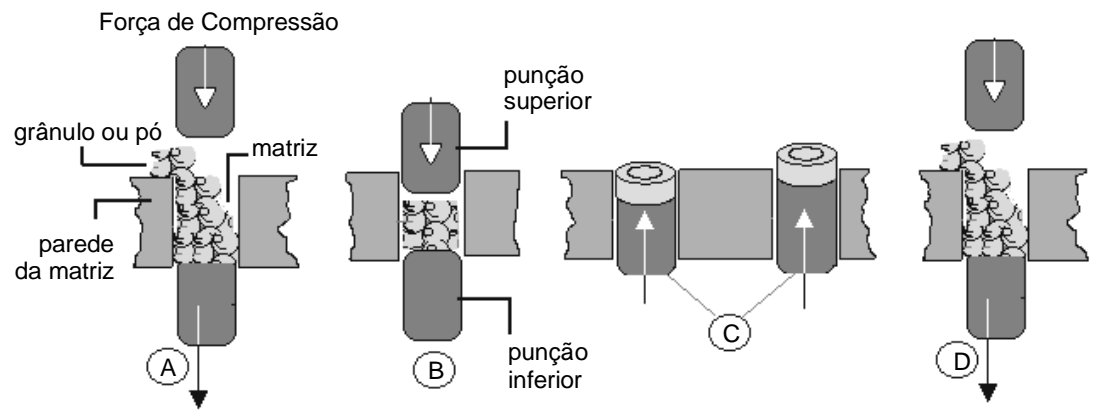

Figura 6 - Seqüência de produção de comprimidos em compressora (Villa Jato, 1997)

tamanho dos grânulos. As farmacopéias preconizam uma dureza, ou resistência ao esmagamento, de no mínimo $30 \mathrm{~N}$, e uma perda de pó por ação do atrito, ou friabilidade, de no máximo, 1,5\%. A dureza é determinada pela aplicação radial de força sobre o comprimido em um instrumento denominado durômetro (Figura 7) e a friabilidade, pela submissão dos comprimidos a 100 quedas, de altura constante, em friabilômetro (Figura 8). Os comprimidos são submetidos a 100 ciclos no aparelho que obedece a padrões internacionalmente aceitos e a friabilidade corresponde a perda de pó causada pela queda/atrito, devendo corresponder a uma perda máxima de 1,5\% do peso total dos comprimidos.

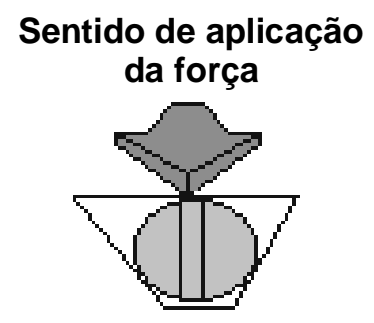

Figura 7. Ilustração do sentido de aplicação de força radial sobre comprimidos no teste de dureza

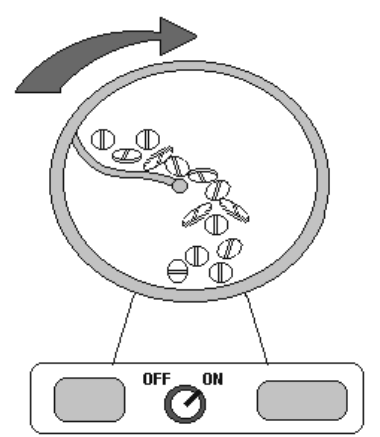

Fiabrilômetro "Roche"

Figura 8. Ilustração do funcionamento de um friabilômetro

\section{Método}

Uma vez apresentadas as características gerais da produção de líquidos, semi-sólidos e sólidos, passa-se à apresentação da pesquisa realizada neste trabalho.

O estudo tem como principal objetivo investigar quais são os principais fatores que interferem no scaling up de processos de produção de formas farmacêuticas sólidas, semi-sólidas e líquidas. Tal investigação foi realizada com base na opinião dos responsáveis pelo desenvolvimento de novas formulações e/ou dos responsáveis pela etapa de transferência de escala na produção em empresas nacionais. A pesquisa foi desenvolvida em empresas que têm por hábito o desenvolvimento, completo ou parcial, de formulações e somente foi considerada completa quando se conseguiu informações relacionadas a problemas de scaling up de formulações pertencentes aos estados físicos sólido, líquido e semi-sólido.

A obtenção de dados foi realizada através de entrevistas qualitativas orientadas pelo pesquisador, através de questões abertas, buscando-se obter dados sobre a visão de cada entrevistado em relação ao assunto proposto. Três entrevistas foram realizadas. Dois entrevistados tiveram suas entrevistas gravadas para posterior transcrição, enquanto que para um deles não foi possível realizar a gravação, sendo os dados registrados manualmente. As entrevistas foram realizadas durante o mês de junho de 2000 com farmacêuticos industriais que atuam em empresas farmacêuticas nacionais. Procurou-se profissionais de empresas com mais de 20 anos no mercado, cujos produtos são distribuídos para vários estados do país. Os farmacêuticos entrevistados apresentam, aproximadamente, 10 anos de experiência em indústria, período este distribuído entre tarefas relacionadas ao desenvolvimento, produção e controle de qualidade dos medicamentos. Os entrevistados tiveram suas identidades mantidas em sigilo, sendo denominados de entrevistados 1,2 e 3 . A Tabela 1 resume as características das entrevistas e dos entrevistados 
Tabela 1 - Recursos empregados nas entrevistas e características dos entrevistados

\begin{tabular}{llll}
\hline & Entrevistado 1 & Entrevistado 2 & Entrevistado 3 \\
\hline $\begin{array}{l}\text { Recurso empregado na } \\
\text { entrevista }\end{array}$ & Manuscrito & Gravação e transcrição & Gravação e transcrição \\
\hline Formação profissional & Farmacêutico industrial & Farmacêutico industrial & Farmacêutico industrial \\
\hline Experiência & Em indústria nacional & Em indústria nacional & $\begin{array}{l}\text { Em indústria multinacional sediada no } \\
\text { Brasil e em indústria nacional }\end{array}$ \\
\hline Tempo de experiência & Cerca 10 anos & Cerca de 10 anos & $\begin{array}{l}\text { Cerca de 7 anos em multinacional e de 2 } \\
\text { anos em indústria nacional }\end{array}$ \\
\hline $\begin{array}{l}\text { Áreas que apresentam } \\
\text { experiência }\end{array}$ & $\begin{array}{l}\text { Desenvolvimento, produção e } \\
\text { controle de qualidade }\end{array}$ & $\begin{array}{l}\text { Desenvolvimento, produção e } \\
\text { controle de qualidade }\end{array}$ & $\begin{array}{l}\text { Desenvolvimento, produção e controle de } \\
\text { qualidade }\end{array}$ \\
\hline
\end{tabular}

\subsection{Roteiro das entrevistas}

O roteiro utilizado para conduzir as entrevistas consistiu em quatro perguntas:

1. Que tipos de produtos são desenvolvidos na empresa onde atuam ou atuaram?

2. Quais são os equipamentos empregados no desenvolvimento da forma farmacêutica em escala de bancada ou piloto?

3. Quais são os equipamentos empregados na escala industrial?

4. Quais especificações de qualidade (da forma farmacêutica em questão) são afetadas na transferência de escala?

\section{Tipos de produtos}

Uma vez definido o tipo de entrevista e as peculiaridades de cada entrevistado na Tabela 1, apresenta-se, a seguir (Tabela 2), os resultados do primeiro questionamento, ou seja, "quais os tipos de produto elaborados pelas empresas onde os entrevistados atuam?’.

Conforme se observa na Tabela 2, a empresa onde atua o entrevistado 1 se diferencia das demais, já que sua linha de produtos envolve injetáveis. O processo produtivo destes últimos é bastante peculiar, envolvendo ambientes extremamente limpos (denominados áreas brancas), onde os níveis de contaminação microbiana são quase nulos. Isto se consegue pela aplicação de normas especiais de higiene, muito mais rigorosas do que aquelas executadas nos setores produtivos das outras empresas listadas. Além disso, na empresa 1 se produz líquidos de uso oral, obtidos por fermentação biológica de uma levedura. O processo de produção deste tipo de medicamento também é bastante diferenciado daquele empregado na maioria das formas farmacêuticas líquidas.
Com relação às formas sólidas, comprimidos e cápsulas, esta empresa atualmente terceiriza a produção, já que representam o menor volume de vendas da mesma, mas no passado ela também fabricava sólidos. Os injetáveis de até $50 \mathrm{~mL}$ (pequeno volume) e o fermentado biológico lideram a lista de vendas, seguidos dos semi-sólidos (cremes e pomadas) e por último dos produtos sólidos.

O entrevistado 2 trabalha em uma empresa onde predominam os sólidos, comprimidos em primeiro lugar e cápsulas em segundo, compreendendo cerca de $60 \%$ da produção. A empresa fabrica também formas líquidas orais e de uso externo (pele), tanto na forma de soluções ou suspensões, bem como de cremes e pomadas. Essa empresa fabricava comprimidos revestidos, denominados drágeas, mas estes produtos foram retirados da linha de produção a cerca de 6 anos atrás.

O entrevistado 3 atua em uma empresa onde também predominam as formas sólidas, com uma distribuição semelhante à apresentada pela empresa 2. Esse farmacêutico trabalhou em uma multinacional que, embora, também se centrasse na produção de sólidos, empregava equipamentos e processos mais sofisticados, dispondo de recursos tecnológicos mais caros e atualizados, o que permitia a produção de formulações igualmente mais elaboradas, do ponto de vista tecnológico.

\section{Conceito de desenvolvimento de produto}

O questionamento seguinte se referia "aos tipos de equipamento empregados no desenvolvimento de produtos nas escala de bancada e piloto". Entretanto, para responder a este questionamento, os entrevistados foram obrigados, anteriormente, a conceituar o que se denomina "desenvolvimento de produto" nas suas empresas.

Todos os entrevistados afirmaram que nas empresas nacionais o desenvolvimento é realizado a partir de 
Tabela 2 - Resumo dos tipos de produtos elaborados pelas empresas onde os farmacêuticos atuam

\begin{tabular}{llll}
\hline & Entrevistado 1 & Entrevistado 2 & Entrevistado 3 \\
\hline Líquidos: & $\begin{array}{l}\text { injetáveis de pequeno volume, soluções orais, } \\
\text { sabonetes, fermentados biológicos }\end{array}$ & soluções, suspensões & soluções, suspensões \\
\hline Semi-sólidos: & pomadas e cremes & pomadas, cremes e pastas & pomadas, cremes e pastas \\
\hline Sólidos & $\begin{array}{l}\text { comprimidos, comprimidos revestidos, sabonete } \\
\text { (produtos terceirizados). }\end{array}$ & comprimidos, cápsulas & comprimidos, cápsulas \\
\hline
\end{tabular}

Tabela 3 - Características das empresas no que se refere ao desenvolvimento de produtos e à existência física do setor correspondente

\begin{tabular}{lll}
\hline Entrevistado 1 & Entrevistado 2 & Entrevistado 3
\end{tabular}

\begin{tabular}{|c|c|c|c|}
\hline $\begin{array}{l}\text { Quanto à existência física de um } \\
\text { setor de desenvolvimento, na } \\
\text { empresa onde atuam ou atuaram }\end{array}$ & Não existe & Não existe & $\begin{array}{l}\text { Multinacional: Sim existe } \\
\text { Nacional: Sim existe, mas } \\
\text { pouco equipado }\end{array}$ \\
\hline $\begin{array}{l}\text { Quanto à realização de } \\
\text { desenvolvimento de produtos, na } \\
\text { empresa onde atuam ou atuaram }\end{array}$ & $\begin{array}{c}\text { Desenvolvimento } \\
\text { parcial }\end{array}$ & $\begin{array}{c}\text { Desenvolvimento } \\
\text { parcial }\end{array}$ & $\begin{array}{l}\text { Multinacional: } \\
\text { Desenvolvimento parcial } \\
\text { Nacional: } \\
\text { Desenvolvimento parcial }\end{array}$ \\
\hline
\end{tabular}

um medicamento modelo, seja uma formulação semelhante e produzida pela própria empresa ou um produto originário de outra empresa, que tenha sido aprovado pelos órgãos de registro. O produto assim desenvolvido é denominado de similar. Ele é obtido a partir de um "desenvolvimento parcial", já que são eliminadas algumas etapas essenciais ao desenvolvimento propriamente dito. Este fenômeno se dá, inclusive, nas filiais de multinacionais farmacêuticas sediadas no Brasil.

A Tabela 3 resume os dados referentes à execução de desenvolvimento de produtos nas empresas dos entrevistados. A própria inexistência de um "desenvolvimento" na acepção da palavra, se reflete na inexistência de um setor fisicamente estabelecido na maioria das empresas farmacêuticas nacionais, o que não se dá na filial multinacional.

Esclarecido o conceito de desenvolvimento, todos entrevistados relataram que freqüentemente, nas empresas nacionais, testam a incorporação da substância ativa na formulação similar que pretendem fabricar, através de alguns ensaios de bancada e empregando instrumentos que serão detalhados a seguir (Tabela 4). Quanto à escala piloto, geralmente os ensaios são executados diretamente na produção, empregando a menor carga ou capacidade que tais equipamentos admitem, mas mantendo ainda funcionalidade.

O entrevistado 3 relatou que a empresa multinacional dispõe de equipamentos de bancada similares aos usados na produção, e que a produção piloto corresponde à fabricação de três lotes de produção, de tamanho original, nos equipamentos originais. $\mathrm{O}$ primeiro lote serve para ajustes de fórmula e os dois seguintes para comprovação e validação do processo.

Maiores detalhes sobre os instrumentos e equipamentos empregados pelos entrevistados podem ser visualizados na Tabela 4.

Os esforços de desenvolvimento dessa empresa concentram-se nos produtos líquidos, e é sobre estes que o entrevistado fornece dados de transferência de escala.

A Tabela 5 reúne os dados fornecidos pelo entrevistado 2, onde sobressai o desenvolvimento de sólidos, especialmente comprimidos. As etapas que antecedem a compressão são: (i) malaxagem, (ii) granulação, (iii) secagem, (iv) mistura de pós e grânulos, e (v) compressão. Observa-se que a empresa não dispõe de equipamentos de bancada para preparação da massa de grânulos (malaxadoras), bem como, de misturadores em formato V. Por esta razão, emprega equipamentos de menor capacidade, também pertencentes à produção, como se fossem escala piloto, utilizando $1 / 5$ da capacidade de produção dos equipamentos originais.

Para as formas líquidas e sólidas são empregados os instrumentos laboratoriais corriqueiros, como béquer, gral e pistilo e batedeira planetária de uso doméstico, partindo, depois, diretamente para a escala de produção nos volumes de 500, 1000 ou 2000 litros, dependendo do tipo de produto. 
Tabela 4. Equipamentos empregados pelo entrevistado 1 nas escalas de bancada e piloto

\section{Entrevistado 1}

\begin{tabular}{c|ccc|ccc}
\hline Escala & \multicolumn{3}{|c|}{ Bancada } & \multicolumn{3}{c}{ Piloto } \\
\hline & Produto & Quantidade & Equipamento & Quantidade & Equipamento & Capacidade \\
\hline \multirow{2}{*}{ Líquido } & soluções orais & 3 litros & Béquer & 5 litros & da Produção & 150 litros \\
& $5 \mathrm{~mL} /$ ampola & 600 ampolas & & 1000 ampolas & & 30.000 ampolas \\
\cline { 2 - 7 } & Fermentado & 5 litros & Recipiente de & 20 litros & da Produção & 37,5 litros \\
& biológico & 1000 flaconetes & fermentação & 4000 flaconetes & & 7.500 flaconetes \\
\hline
\end{tabular}

Tabela 5 - Equipamentos empregados pelo entrevistado 2 nas escalas de bancada e piloto

\section{Entrevistado 2}

\begin{tabular}{|c|c|c|c|c|c|c|}
\hline \multirow[t]{2}{*}{ Escala } & \multicolumn{3}{|c|}{ Bancada } & \multicolumn{3}{|c|}{ Piloto } \\
\hline & Produto & Quantidade & Equipamento & Quantidade & Equipamento & Capacidade \\
\hline $\begin{array}{r}\text { Líquido e } \\
\text { Semi sólido }\end{array}$ & $\begin{array}{l}\text { soluções, cremes, } \\
\text { suspensões }\end{array}$ & 5 litros & $\begin{array}{c}\text { béquer, gral, } \\
\text { batedeira planetária }\end{array}$ & - & $\begin{array}{c}\text { da Produção } \\
\text { Tanques }\end{array}$ & $500,1000,2000$ litros \\
\hline \multirow[t]{3}{*}{ Sólido } & $\begin{array}{l}\text { Grânulos para } \\
\text { comprimidos }\end{array}$ & - & - & $25 \mathrm{~kg}$ & $\begin{array}{l}\text { Malaxadora } \\
\text { piloto }\end{array}$ & $\begin{array}{c}\text { Equip. Produção } \\
\text { malaxadora } 150 \mathrm{~kg}\end{array}$ \\
\hline & $\begin{array}{c}\text { Mistura de pós } \\
\text { para } \\
\text { comprimidos }\end{array}$ & - & - & $20 \mathrm{ou} 100 \mathrm{~kg}$ & $\begin{array}{c}\text { Misturadores V de } \\
\text { capacidade } 20 \text { e } 100 \mathrm{~kg}\end{array}$ & $\begin{array}{l}\text { Equip. Produção } \\
\text { Misturador } 200 \mathrm{~kg}\end{array}$ \\
\hline & $\begin{array}{c}\text { Comprimidos } \\
7 \mathrm{~mm} \phi \\
9 \mathrm{~mm} \phi \\
13 \mathrm{~mm} \phi\end{array}$ & - & - & $\begin{array}{c}\text { Unidades } \\
100.000 \\
70.000 \\
30.000\end{array}$ & $\begin{array}{r}\text { da Produção } \\
\text { Compressora }\end{array}$ & $\begin{array}{c}\text { Unidades } \\
500.000 \\
350.000 \\
2 \times 150.000\end{array}$ \\
\hline
\end{tabular}

O entrevistado 3 possui experiência com o desenvolvimento de sólidos, especificamente comprimidos, em equipamentos de bancada ERWEKA, marca alemã conhecida no meio farmacêutico. A capacidade destes equipamentos é de cerca de $4 \mathrm{~kg}$. A próxima escala de desenvolvimento é feita utilizando equipamentos de produção, porém na sua menor capacidade.

Segundo o entrevistado, geralmente as empresas nacionais e multinacionais não investem em equipamentos piloto, pois o custo dos mesmos se aproxima de $80 \%$ do preço do equipamento industrial. Desta forma, na ausência de tais equipamentos, executa-se o teste piloto diretamente no equipamento de produção, obedecendo o tamanho de lote original (na empresa multinacional) ou a menor capacidade de produção do equipamento, geralmente $30 \%$ do tamanho do lote original (na empresa nacional). Nas empresas nacionais o procedimento é semelhante, porém estas não dispõem, também, dos equipamentos de bancada (ver Tabela 6).

Os instrumentos empregados na escala de bancada para líquidos e semi-sólidos são vidrarias, cuja capacidade máxima é de 10 litros. No caso de homogeneização incluem-se recipientes de aço inoxidável de $10 \mathrm{~L}$ ou mais de capacidade, providos com agitação de hélice. A escala piloto já é executada na menor capacidade dos recipientes de produção.

A Tabela 6 resume os dados fornecidos pelo entrevistado 3 sobre equipamentos empregados nas escalas de bancada e piloto, em empresa multinacional e nacional.

Com respeito à questão número três, "quais são os equipamentos empregados na escala industrial?" esta ficou esclarecida nas próprias respostas dadas, pelos entrevistados, à questão número dois. $\mathrm{Na}$ realidade, não existe distinção entre os equipamentos piloto e industrial, com algumas exceções, conforme demonstram as Tabelas 4, 5 e 6. A capacidade destes equipamentos corresponde à escala industrial e estão descritas nestas mesmas tabelas.

\section{Problemas de scale up}

O quarto questionamento se refere à "incidência de problemas de scale up nas formas farmacêuticas $e$ quais são as características de qualidade que são afetadas nessa transferência”. 
perda de $3 \%$, se surpreendeu com o aumento desta perda para $10 \%$, após a modificação do sistema produtivo. Atualmente, a solução paliativa dada pela empresa contratada foi o reaproveitamento do resíduo de um lote, no próximo lote de produção.

\subsection{Entrevistado 2 - problemas e soluções de scale up}

- Segundo o entrevistado 2, problemas de formas líquidas (soluções) estão associados à maior ou menor solubilidade do fármaco no solvente. Um problema indesejado é quando o fármaco se solubiliza bem nos volumes preparados na escala de bancada, mas precipita nos tanques de preparação. Pode-se atribuir este tipo de fato à escolha inadequada de adjuvantes ou a condições do equipamento de bancada que não podem ser reproduzidos adequadamente na produção, como fornecimento de calor e agitação do sistema de mistura. O entrevistado 2 considera fundamental a manutenção da agitação durante toda a produção, até o momento do envase, seja este executado no mesmo dia ou não.

- As suspensões são sistemas dispersos, onde a substância ativa é insolúvel no veículo líquido, e o grande desafio, segundo o entrevistado, é encontrar um agente suspensor (liquido viscoso) que mantenha as partículas do fármaco homogeneamente distribuídas por todo o volume de produto. Na transposição de escala entre a bancada e produção, o comportamento do agente suspensor muda, em função do tipo de agitação do sistema, fato observado como perda de consistência. Assim, a velocidade de sedimentação do fármaco aumenta, o que é indesejado em uma suspensão. Neste caso, realizam-se testes de sedimentação com o produto e se aumenta a concentração de agente suspensor, mas infelizmente às vezes é preciso desprezar o lote defeituoso.

- Com relação aos comprimidos, segundo a experiência do entrevistado 2, não se consegue resultados satisfatórios quando se emprega uma compressora de apenas um par de punções (máquina excêntrica) como escala piloto, pois o sistema de compressão de uma máquina rotativa, contendo vários pares de punções, é diferente, não se aproveitando os parâmetros já ajustados no sistema excêntrico, como força de compressão, peso do comprimido e outros. Assim sendo, optam pela produção de um lote reduzido no equipamento da escala de produção, onde são ajustados os parâmetros de compressão diretamente.

- Algumas vezes aparecem problemas nos comprimi- dos produzidos nestes pequenos lotes, especialmente sua incapacidade de desintegração e dissolução nos ensaios de controle de qualidade. Se o problema é falta de dissolução, atribui-se à quantidades excessivas de aglutinante. Portanto, deve-se reduzir a quantidade do mesmo. Se o problema é tempo de desintegração elevado, além do aglutinante, deve-se reduzir também a força de compressão.

- Algumas vezes, durante o desenvolvimento ou durante a produção corrente de uma fórmula registrada, recebe-se novo lote de matéria-prima e/ou adjuvante proveniente de fornecedor não habitual. É comum que o comprimido sofra modificações nas suas especificações de qualidade, dureza, friabilidade, desintegração e dissolução. Nestes casos, o lote é triturado e o pó obtido é granulado novamente para ser submetido a nova compressão. A compressão deve sofrer modificações nos seus parâmetros, na expectativa de que o comprimido venha a cumprir as especificações de qualidade, e em alguns casos, a última opção é modificar a fórmula, adicionando-se outros adjuvantes para se contornar o problema.

- A transposição de escala entre os malaxadores não é normalmente problemática por serem equipamentos de grande capacidade nas escalas piloto e industrial. De qualquer forma, deve-se preocupar em transpor adequadamente os tempos de malaxagem, proporcionalmente ao volume de produção. O tempo de secagem do grânulo é outro parâmetro que deve ser transposto com cuidado, pois a umidade residual do grânulo afeta significativamente a qualidade do comprimido produzido. Ao se aumentar (na escala industrial) a quantidade de granulado a ser secada, deve-se garantir a homogeneidade de umidade nos mesmos, pois grânulos muito úmidos produzem comprimidos pouco resistentes e suscetiveis de contaminação por microrganismos. Grânulos muito secos provocam o "capping” de comprimidos, ou seja, a rachadura e quebra horizontal.

- O excesso de força de compressão pode causar capping em até 72 h. Neste caso, deve-se reduzir a força de compressão e, caso os comprimidos continuem quebradiços no teste de friabilidade, deve-se triturá-los e proceder a re-granulação do pó obtido.

- O excesso do lubrificante estearato de magnésio causa redução da dureza do comprimido, independente do tipo de fármaco que estiver sendo produzido. A solução nesta situação é substituir por talco ou reduzir a quantidade de estearato na fórmula. Deve-se ter atenção, pois o talco pode afetar os tempos de desintegração e dissolução 
do comprimimido.

- As cápsulas não representam problemas de transposição de escala. Caso sejam preenchidas com grânulos, poderão ocorrer os problemas de granulação citados anteriormente. Se o granulado não apresentar uma granulometria adequada não caberá dentro da cápsula. Nesta situação, deve-se proceder, adequadamente, o calculo o tamanho do grânulo para preencher a cápsula. Então, submeter tais grânulos à homogeneização com talco e estearato de magnésio, em misturador em V.

\subsection{Entrevistado 3 - problemas e soluções de scale up}

- Segundo o entrevistado 3, o grande problema nos líquidos é o aparecimento de precipitado. O entrevistado relata que estes problemas são mais comuns quando se trata de uma mistura de vários fármacos com diferentes solubilidades e que existe a adição de adjuvante para garantir a solubilidade de algum deles. Neste caso, os testes de bancada auxiliam detectar precipitados e a grande saída é sempre preparar a mistura de solventes, na escala industrial, para, por último, incorporar a (s) substância (s) ativa (s).

- O tempo de solubilização de substâncias ativas no solvente é determinado empiricamente na escala piloto ou na produção retirando-se amostras pela válvula de descarga até que não haja mais sólidos em suspensão. Se o processo demorar $10 \mathrm{~min}$, se estabelece um tempo um pouco maior, 15 a 20 min, para garantir que todos os fármacos tenham se solubilizado e se padroniza este tempo de agitação.

- Nas suspensões e emulsões a homogeneidade do tamanho de partícula é fundamental para a estabilidade de ambas. Assim, dependendo do tipo de processo produtivo, preocupa-se em empregar moinhos na escala industrial que reproduzam a mesma distribuição de tamanho de partículas, que a obtida na escala de bancada. $O$ indicador de qualidade entre as escalas é o estudo de estabilidade dos cremes (emulsões) que se dá em estufa. As amostras não poderão sofrer quebra da emulsão, com separação de fases, em tempos diferentes daqueles apresentados no estudo de bancada. As suspensões, por sua vez, deverão ter a viscosidade de sua fase dispersante controlada pelo emprego de matérias-primas de granulometria conhecida. Portanto, a padronização do tamanho de partícula do agente de viscosidade, bem como a padronização do fornecedor e do tipo de moinho, são fundamentais para a homogeneidade de suspensões $e$ emulsões.

- Quando uma formulação apresenta qualquer problema durante a produção, e se suspeita de alguma dos componentes, (matéria-prima fornecedores novos), a solução é executar o scale down, ou seja, remover os componentes da fórmula e testá-la após cada remoção, para encontrar o componente responsável pela instabilização.

- Com relação às formas farmacêuticas sólidas, os principais problemas no scale up acontecem em comprimidos e drágeas e se constituem em: $\boldsymbol{a}$ mistura de pós não aceitar compressão, friabilidade alta, dureza excessiva, capping ou aderência do pó, ou de granulado, aos punções.

- A alta friabilidade e capping são causados por grânulos muito secos. De uma forma geral, a umidade residual do grânulo deve estar entre 3 e $4 \%$.

- O capping poderá ser causado por granulometria caso se pretenda preparar um comprimido pequeno com grânulos muito grandes. Comprimidos de até $11 \mathrm{~mm}$ de diâmetro devem ser preparados com grânulos de1 mm ou menos. Comprimidos maiores que $11 \mathrm{~mm}$ devem ser preparados com grânulos de 1,5 mm, no máximo.

- A aderência de pós aos punções é determinada pelo excesso de umidade nos grânulos. Reduzir a umidade residual a 3 ou 4\%, ou aumentar a concentração de adjuvantes antiaderentes, geralmente resolve o problema de aderência.

- A dureza do comprimido está relacionada com a quantidade de aglutinante presente ou à força de compressão da máquina e pode comprometer o tempo de desintegração do mesmo. Deve-se ajustar a quantidade de aglutinante, a força de compressão para cada tipo de formulação, durante o scaling up, e padronizar. Como última opção adicionar desintegrantes potentes como glicolato sódico de amido (Explotab ${ }^{\circledR}$, Explocel $\AA$ ).

- Pode haver quebra excessiva de núcleos de comprimido durante o drageamento, diminuindo o rendimento do processo industrial. Para a preparação de drágeas (comprimidos revestidos) devese utilizar núcleos com dureza de $80 \mathrm{~N}$ obtidos por compressão, pois o turbilhonamento dos comprimidos durante o drageamento pode causar quebra dos mesmos, caso estejam com dureza mais baixa.

\section{Análise e discussão das informa-} ções 
Nas indústrias nacionais o número de profissionais farmacêuticos é sempre reduzido, e a própria rotina do farmacêutico contribui para a inexistência formal desta tarefa. Poucos ensaios laboratoriais são executados, em geral, sem muito rigor científico, empregando vidrarias de pequeno porte. Entre as empresas citadas pelos entrevistados, são poucas aquelas que possuem um setor definido, ou seja, um laboratório exclusivo para desenvolvimento de produto. É importante salientar que todos os entrevistados confirmaram que estes testes são desenvolvidos a partir de uma formulação modelo que já tenha demonstrado eficácia farmacológica, ou comportamento adequado nos equipamentos de produção. O desenvolvimento formal, iniciando-se na fase de pré-formulação e se estendendo até o registro do medicamento, é fato pouco frequiente nas empresas brasileiras, incluindo-se aquelas que se dedicam exclusivamente ao desenvolvimento terceirizado de produto.

As empresas justificam este fato aos seguintes fatores limitantes:

- custos e dificuldades envolvidas na existência de uma relação muito diversificada de matériasprimas na empresa, o que envolveria qualificação de fornecedores, quantidades mínimas a serem adquiridas, que nem sempre são as desejadas, investimentos na elaboração de ensaios de controle de qualidade para os insumos novos;

- custos relacionados a investimentos em equipamentos de bancada;

- custos da contratação de mão-de-obra especializada.

Resta, então, às empresas nacionais trabalhar com formulações tradicionais, nas quais se emprega uma tecnologia primária. Quanto às filiais multinacionais, estas se diferenciam das empresas nacionais no que se refere aos gastos com os ensaios de bancada, onde são empregados equipamentos, nos quais o farmacêutico tem a liberdade de preparar quantidades da ordem de quilogramas para posterior descarte.

A política de registro de medicamentos adotada pelo Ministério da Saúde no Brasil de certa forma contribui para a manutenção deste quadro. É permitido às empresas "copiarem" formulações bem sucedidas de outras empresas e registrá-las sob a denominação de produto similar. O medicamento similar é entendido como sendo aquele que possui a mesma substância ativa, na mesma dose e no mesmo tipo de forma farmacêutica, não necessariamente apresentando os mesmos adjuvantes. A indústria deverá comprovar a validade do processo de fabricação através dos indicadores de qualidade químicos e físico-químicos, mas não dos farmacológicos, ou seja, não é necessário comprovar através de estudos em humanos ou em animais que o medicamento similar apresenta a mesma eficácia do medicamento usado como modelo.

Explica-se este tipo de desenvolvimento também, pelo fato de que um desenvolvimento completo de uma forma farmacêutica se dá quando o fármaco é recém descoberto, nunca foi transformado antes e que torna essencial a realização da etapa de pré-formulação. As moléculas ativas consumidas pela indústria brasileira já tiveram , em sua maioria, as patentes vencidas, tendo sido lançadas no mercado por multinacionais nas formas comprimidos, cápsulas, soluções ou outras.

Os setores industriais onde os entrevistados trabalham produzem tanto formas sólidas e líquidas, quanto semi-sólidas, porém com ênfase de vendas diferenciada. Diante das experiências em produção, foram unânimes em afirmar que os problemas de transferência de escala, e mesmo de produção, predominam nos comprimidos.

Segundo os entrevistados, são muitas as características de qualidade dos comprimidos a serem otimizadas e quando se ajusta uma delas, as outras não necessariamente estão nos seus valores ótimos. São elas: dureza, friabilidade, tempo de desintegração e tempo de dissolução. De uma forma mais ou menos intensa, todas são afetadas pelos tipos e quantidades dos seguintes adjuvantes: aglutinante, desintegrante e diluente, e pela força de compressão da máquina. Esta última, por sua vez, nas máquinas rotativas, é função da carga de pó ou grânulo que cai dentro da matriz. Assim, pelo menos 30 minutos do setup de produção de comprimidos são dedicados aos ajustes de peso do comprimido e força de compressão, sem os quais pode-se danificar a compressora.

Antes da compressão, entretanto, encontram-se as etapas de preparação da formulação propriamente dita e se não forem respeitados alguns parâmetros como umidade residual nos grânulos, tamanho de grânulo ou granulometria de pós, os comprimidos resultarão defeituosos, fato que pode acontecer durante o scaling up ou em qualquer lote de produção. $\mathrm{O}$ defeito denominado capping ou decapamento (Figura 9A) é o mais indesejado, principalmente porque pode acontecer até $72 \mathrm{~h}$ após a preparação. Quando ocorre, são duas as alternativas: desprezar todo o lote ou retriturar os comprimidos para reiniciar o processo produtivo. Esta última alternativa pode ser perigosa, pois o fármaco manipulado já foi exposto às condições ambientais de luz e umidade e, provavelmente, a vida em prateleira do comprimido refeito será menor. 


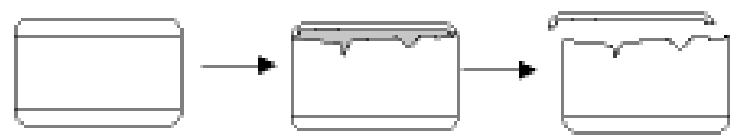

Figura 9A - Capping ou decapamento (Villa Jato, 1997)

Figura 9B - Laminação (Villa Jato, 1997)

Um outro problema de produção é a aderência aos punções, com ocorrência de laminação (Figura 9B) do comprimido, ou ainda, destruição total do mesmo (Figura 10) com comprometimento da produção que deve ser interrompida para remoção de pedaços de comprimidos aderidos aos punções ou à matriz.

Figura 10 - Aderência dos punimidos aos punes e matriz

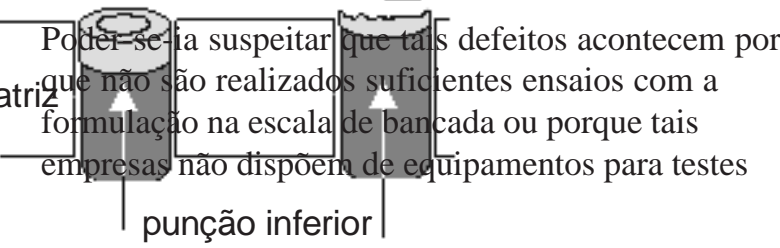

piloto, conforme descrito anteriormente. Esta hipótese é confirmada por Nyqvist (1994), e a própria literatura acumula exemplos semelhantes obtidos em testes acadêmicos ou mesmo junto a empresas de grande porte, conforme pode-se observar na Tabela 8 e nas referências que se seguem (Nyqvist, 1989; Ogawa et al., 1994; Bueb, Warnke, Bauer, 1994). Por enquanto, são vários os relatos sobre os problemas e suas possíveis causas; o que inexiste é uma ferramenta que possa prever tais defeitos, a partir dos ensaios de bancada ou piloto, e prevenir as suas ocorrências.

O entrevistado 3 relatou que a impossibilidade de rodar um teste piloto empregando a capacidade total da linha de produção às vezes leva ao surgimento de problemas que são função do volume de produção e do tempo de processo. Certa vez, um comprimido produzido em pequena quantidade na linha de produção apresentou características adequadas, mas ao ser fabricado no tamanho de lote definitivo, apresentou decapagem_ $48 \mathrm{~h}$ após a produção, com conseqüente descarte do lote. Os farmacêuticos entrevistados atribuíram a ocorrência destes custos a um scaling up incompleto ou deficiente.

Tabela 8 - Problemas em comprimidos e suas possíveis causas (Vila Jato, 1997)

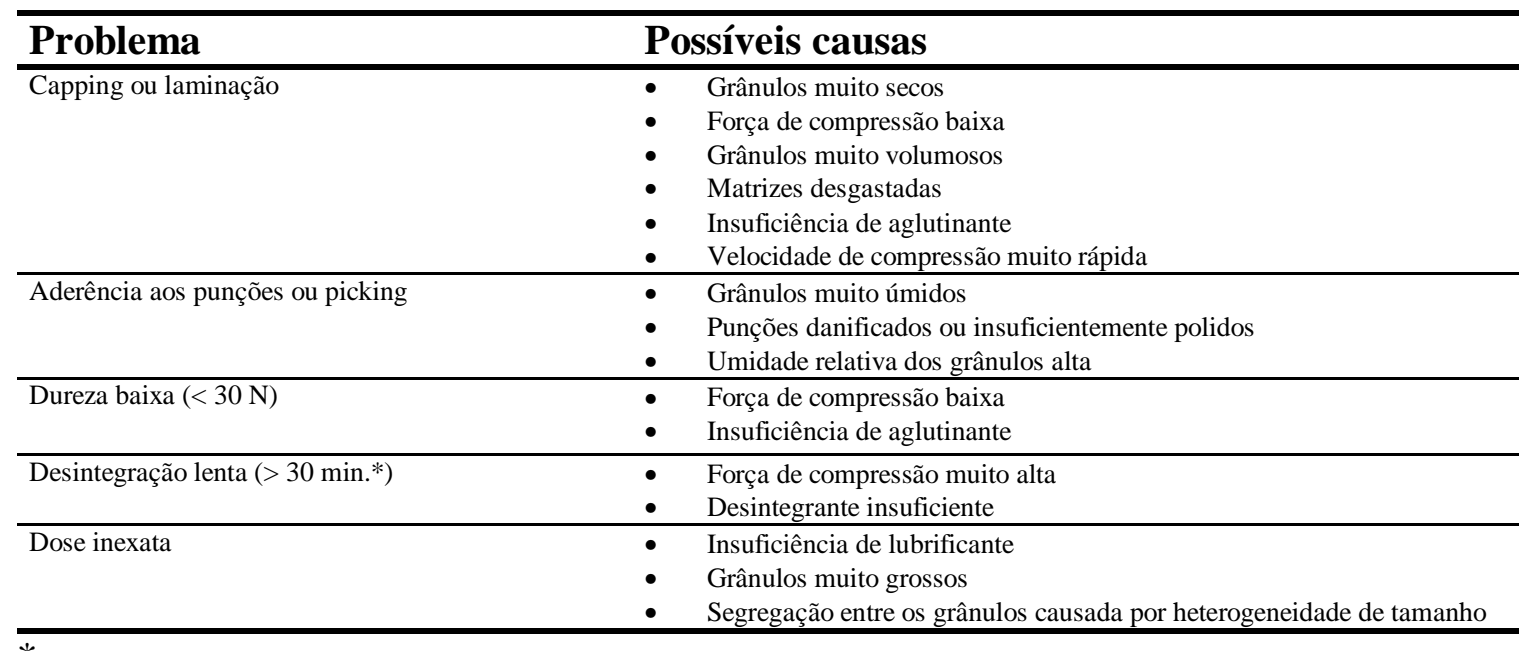

* Comprimidos convencionais. 
proporção de scale up consiste na razão entre a maior e a menor escala de produção. O valor de partida para o cálculo da escala de bancada é a própria capacidade da linha de produção. Assim, se a capacidade do tanque de produção de uma forma líquida for de 4.000 L, dever-se-á produzir um volume de $400 \mathrm{~L}$ em escala piloto ampliada e $40 \mathrm{~L}$ num piloto reduzido, sendo que as amostras iniciais sejam de $4 \mathrm{~L}$ na escala de bancada, onde são realizados os testes preliminares.

Bisio e Kabel (1985) afirmam que proporções de scale up típicas entre equipamentos de laboratório e a planta piloto se encontram numa faixa de 500-1000 e entre a escala piloto e a escala industrial entre 200500 , valores superiores àqueles difundidos no meio farmacêutico.

A partir dos valores relatados pelos entrevistados, e considerando-se as limitações das empresas, é possível deduzir as proporções de scale up (razão entre a menor e a maior escala que desenvolvem) que aparecem na Tabela 9.

Os resultados apresentados suscitam os seguintes raciocínios. Seja o scale up conduzido completamente ou não, são relatados os mesmos tipos de defeitos na produção industrial de comprimidos. O que ainda não está claro é se a incidência de defeitos é maior ou mais frequiente quando a proporção e o número de etapas de scale up é menor (empresas nacionais). Esta questão permanece em aberto e merece investigação. $\mathrm{O}$ entrevistado 3 acrescenta que um fator que deve ser considerado é o tempo de produção, já que, quando se executa somente $30 \%$ do lote original na fase piloto, às vezes não há tempo para se detectar determinados defeitos que virão a aparecer na rodada do lote completo.

Ainda sobre os comprimidos, vale adicionar uma informação. Quando o produto está completamente desenvolvido, registrado e em produção, a modificação das características físicas dos adjuvantes ou da substância ativa (por troca de fornecedor, p.ex.) pode causar os mesmos defeitos já relacionados e muitas vezes provocar o retrocesso da produção ao nível de desenvolvimento da fórmula, testes e novo scale up.

Com relação aos equipamentos os entrevistados divergiram em suas impressões. Segundo a experiência do entrevistado 2 com compressoras excêntricas (apenas 1 par de punções), não compensa desenvolver e testar uma fórmula para depois transferi-la para uma máquina de comprimir rotativa, cujo princípio de funcionamento é diferente da primeira. Já o entrevistado 3 empregou a compressora excêntrica inclusive no desenvolvimento de comprimidos efervescentes (geralmente problemáticos), e teve ótimos resultados que foram aproveitados na transferência de escala. Não existe clareza se o sucesso ou insucesso no uso de equipamento excêntrico como escala piloto de comprimidos é, ou não, dependente do tipo de formulação que se está trabalhando, dúvida que poderá ser esclarecida através de estudos futuros.

Observando-se as Tabelas 4, 5, 6 e comparando-as com a Tabela 9 , percebe-se que existe um maior acesso a instrumentos para a execução de um scale up completo em produtos semi-sólidos e líquidos. Em geral os problemas ocorridos nos líquidos são muito menos frequientes, sendo os mais preocupantes aqueles relacionados à sedimentação em suspensões. Acredita-se que um scale up bem feito, precedido por um desenvolvimento de formulação calcado em bases mais científicas, com testes envolvendo múltiplas concentrações e tipo de adjuvantes, pudesse até impedir estas surpresas indesejadas.

Esta percepção também é válida para os semi-sólidos. Para estes últimos, o desenvolvimento de formulação apresenta um caráter um pouco diferenciado dos comprimidos. É muito comum a aquisição de matérias-primas novas para a realização de testes, já que é alta a freqüência de lançamento de novas ceras que apresentam características auto-emulsionantes, aspecto brilhante, boa espalhabilidade sobre a pele, compatibilidade com outros adjuvantes, estabilidade física, e outras características tentadoras para o formulador.

Tabela 9 - Proporção de scale up das formas farmacêuticas produzidas nas empresas onde atuam os entrevistados

\begin{tabular}{|c|c|c|c|c|}
\hline \multirow[b]{2}{*}{ Produto } & \multirow{2}{*}{$\begin{array}{c}\text { Entrevistado } 1 \\
\text { Empresa nacional }\end{array}$} & \multirow{2}{*}{$\begin{array}{c}\text { Entrevistado } 2 \\
\text { Empresa nacional }\end{array}$} & \multicolumn{2}{|c|}{ Entrevistado 3} \\
\hline & & & Empresa nacional & Empresa multinacional \\
\hline soluções orais & 50 & - & - & - \\
\hline Fermentado biológico & 7,5 & - & - & - \\
\hline soluções, cremes, suspensões & & 400 & 666 & 1000 \\
\hline Grânulos para comprimidos & & 6 & 3,3 & $1666-500$ \\
\hline Mistura de pós para comprimidos & & 100 & 3,3 & $666-200$ \\
\hline Comprimidos & & 5 & 3,3 & $1 *$ \\
\hline
\end{tabular}

* Menor escala é um lote original de produção. 
Por essa mesma razão, as empresas do setor de cosméticos costumam executar um desenvolvimento mais formalizado de produtos semi-sólidos (cremes, loções cremosas, bronzeadores, produtos para o tratamento dos cabelos), iniciando na etapa de préformulação e estendendo-se até o registro do produto no Ministério da Saúde (8 fases apresentadas nas considerações iniciais deste trabalho). Essas empresas são forçadas a se comportarem desta maneira, até porque o setor de cosméticos internacional está amplamente protegido por patentes, seus adjuvantes e insumos de formulação complexa são comercializados por nomes fantasia, o que desfavorece a cópia ou desenvolvimento de similares.

Durante as entrevistas, os farmacêuticos não somente relataram os problemas de transposição de escala como também aqueles que ocorrem durante a produção, apresentando causas variadas. Fatos interessantes que foram considerados problemas de transferência de escala são descritos a seguir.

Com relação aos líquidos, o entrevistado 1 considerou o problema de fechamento a quente das ampolas um problema de scaling up porque esta é uma operação industrial que não pôde ser testada na escala de bancada. Com relação aos semi-sólidos, observou-se também um problema de envase. O sistema de agitação para preparação da mistura de creme pode provocar a incorporação de ar no produto final. Esse produto não apresentará envase de volumes uniformes nos frascos, por formação de êmbolos de ar nos dutos de enchimento. A presença de ar no creme só foi reconhecida como problema na escala industrial.

\section{Conclusões}

O presente artigo apresentou uma análise do desenvolvimento de produtos e problemas de transferência de escala observados em empresas farmacêuticas brasileiras. Tais problemas são frequientes e pouco relatados na literatura, por se caracterizarem como conhecimento tácito, adquirido com a experiência prática e transferido de profissional para profissional no ambiente de produção. A importância deste artigo reside na compilação e registro das principais causas e soluções para problemas de scale up encontradas por profissionais, durante a fabricação de formas farmacêuticas sólidas, líquidas e semi-sólidas. Além disso, permite fazer um diagnóstico preliminar das condições de funcionamento dos setores de desenvolvimento de produtos em empresas farmacêuticas.

Farmacêuticos industriais de diferentes empresas, apresentando experiências profissionais distintas, foram questionados quanto ao tipo de produto que desenvolvem nas empresas onde atuam; sobre os equipamentos que dispõem para estudos de bancada e na linha de produção; e a respeito das principais alterações que ocorrem com as formas farmacêuticas na transferência de escala.

Observou-se uma variabilidade muito grande entre os equipamentos empregados em diferentes empresas farmacêuticas nacionais, apesar das empresas apresentarem porte similar. Foram observados desde equipamentos rudimentares até equipamentos de última geração, monitorados por computadores. Atribui-se alguns problemas de scaling up de produtos cujos desenvolvimentos foram terceirizados à discrepância entre o tipo de equipamento empregado no desenvolvimento e aquele da linha de produção.

O desenvolvimento formal de produto, conduzido desde os estudos de pré-formulação até o registro pelo Ministério da Saúde, não acontece nas empresas brasileiras, que costumam partir de medicamentos modelo já comercializados. Detectou-se que dentre os produtos desenvolvidos, as formas sólidas são as que mais freqüentemente apresentam problemas durante a transferência da escala.

Além dos problemas de scaling up, as entrevistas permitiram identificar outros fatores, que podem ser considerados ruídos para o processo de desenvolvimento e produção de formas farmacêuticas, tais como: necessidade de qualificação formal de fornecedores; necessidade de padronização de matériasprimas; ausência de protocolos de desenvolvimento e de scaling up de produtos farmacêuticos. Os órgãos reguladores internacionais, através de comitês, já estão se preocupando com a harmonização de matérias-primas. Tal atitude parece estar sensibilizando a Agência Nacional de Vigilância Sanitária ANVISA, no sentido de normatizar os requisitos mínimos de qualidade para os insumos farmacêuticos. Com respeito a fornecedores, o envolvimento e qualificação destes é responsabilidade da empresa, refletindo a cultura e conceito de qualidade adotado pela mesma.

\section{Referências bibliográficas}

\author{
BISIO, A.; KABEL, R.L. Scale up of Chemical \\ Processes - Converstion from Labortory Scale Tests \\ to Sucessful Comercial Size Design. Wiley- \\ Interscience Publication: New York, 1985. \\ BUEB, W.; WARNKE, G.; BAUER, K.H. Tablet \\ coating methods for very small batches and their \\ suitability for scaling up. Drug Dev. Ind. Phar., v. 20, \\ n. 9 , p. $1555-1569,1994$.
}

COLEMAN, D.E.; MONTGOMERY, D.C. A 
Systematic Approach to Planning for a Designed Industrial Experiment. Technometrics, v.35, n.1, p.1$12,1993$.

GUNTER, B.H. D A Systematic Approach to Planning for a Designed Industrial Experiment. Discussion, Technometrics, v.35, n.1, p.13-14, 1993.

HOFEN W., KORFER M., ZETZMANN, K. Scaleup-Probleme bei der experimentellen Verfharensentwicklung. Chem. Ing. Tech., v. 62, n. 10, s. 805-812, 1990.

KLEIN, G.F. Nova técnica pra adequação em larga escala de formas farmacêuticas líquidas, Pharm. Tech., v.3, n. 3, p. 17-23, Junho 1999.

NYQVIST, H. Influence of Substance properties on scaling up of tablet formulations. Drug Dev. Ind. Phar., v. 15, n. 6 \& 7, p. 957-964, 1989.

OGAWA, S.; KAMIJIMA, T.; MIYAMOTO Y.; MIYAJIMA, M.; SATO, T., TAKAYAMA, K, NAGAI, T. A new attempt to solve the scale up problem for granulation using response surface methodology. J.Pharm. Sciences, 83: (3), p. 439-443, 1994.

VILLA JATO, J.L. Tecnología FarmacéuticaFormas Farmacéuticas. Madrid: Editorial Sintesis, v. II, p.101-150, 1997.

VON ZIMMERMANN, I. Up Scaling Pharmazeutischer Herstellverfahren. Pharm. Ind., 53, n. 4, p. 377-383, 1991.

WEHRLÉ, P.; NOBELIS, P.H.; CUINÉ, A.;

STAMM, A. Scaling up of Wet Granulation. A

Statistical Methodology. Drug Dev. Ind. Phar., v. 19, n. 16, p. 1983-1997, 1993.

\section{Agradecimentos}

Os autores deste trabalho agradecem ao CNPq pelo apoio concedido sob a forma de bolsas de pesquisa. 